\title{
Facilitation of appetitive conditioning with naturalistic conditioned stimuli: CS and US factors
}

\author{
BRIAN CUSATO and MICHAEL DOMJAN \\ University of Texas, Austin, Texas
}

\begin{abstract}
Adding limited female cues to a conditioned stimulus (CS) facilitates conditioned male sexual responding. In two experiments, we examined the mechanisms of this facilitation effect. The color of the female cues on the CS was varied in Experiment 1. Similarity between the CS plumage color and the color of the live female (the unconditioned stimulus [US]) could only partially account for the results. The extent to which the facilitation effect represents a specialization of sexual behavior was examined in Experiment 2 by comparing conditioning with either food or copulation as the US. The CSs with female cues elicited more approach and grab responses regardless of which US was used. However, uniquely sexual conditioned responses (mounts and cloacal contacts) were enhanced only when sexual reinforcement served as the US. These findings suggest that the facilitation effect of female cues represents a general feature of appetitive behavior systems.
\end{abstract}

Laboratory studies of Pavlovian conditioning typically employ training trials in which a conditioned stimulus (CS) precedes the presentation of an unconditioned stimulus (US). The CS is carefully selected so that it elicits little responding and has no special relation to the US at the outset of training. Processes of learning that are activated by such laboratory procedures presumably evolved to facilitate organisms' interactions with events in their natural environment (Hollis, 1982,1997). How might the basic elements of Pavlovian conditioning occur outside the laboratory?

Biologically significant USs no doubt occur in an animal's natural environment, and it is reasonable to suppose that such natural USs may be reliably preceded by other less salient cues that serve as CSs. But, outside the laboratory, a CS that reliably precedes a US is not apt to be completely arbitrary. Rather, potential CSs are bound to have some inherent relation to the US. The CS and US may be different features of the same object (e.g., the sight of food vs. its nutritional value), they may be related spatially, or they may be linked through a causal mediator (e.g., apple trees with healthy leaves are more likely to have tasty and nutritious apples than trees with diseased leaves).

Efforts to relate laboratory-based Pavlovian conditioning phenomena to the natural world of organisms require special considerations. First, the cues or events that reliably predict naturally occurring USs have to be identified. Once identified, these cues or events (i.e., potential CSs)

\footnotetext{
We thank Neil Levens, Scott Lauritzen, and Katherine Kirby for their assistance with data acquisition and scoring of the videotapes. The research and preparation for the manuscript was supported by National Institutes of Health Grant MH39940 and Training Grant MH18837. Correspondence concerning this article should be addressed to $\mathrm{B}$. $\mathrm{Cu}-$ sato (e-mail: cusato@mail.utexas.edu) or M.Domjan (e-mail: domjan@ psy.utexas.edu), Department of Psychology, University of Texas, Austin, Texas 78712 .
}

should be analyzed to determine their critical characteristics. Also of importance is determining whether, and how, naturally occurring CS-US combinations are inherently related. Finally, this inherent relationship should be specifically examined to address the extent to which it affects the course of the learning that occurs.

Some progress in addressing these special considerations has been made in studies of sexual learning in male domesticated quail (Coturnix japonica), a terrestrial galliform species. These birds live in the agricultural fields and grasslands of Japan and Hawaii (Kawahara, 1967; Schwartz \& Schwartz, 1949). However, they tend to avoid very tall or dense vegetation unless they are fleeing from predation (Taka-Tsukasa, 1935; Wetherbee, 1961). In fact, during the breeding season, the male and female of the species prefer to interact in the shorter grass on the edge of clearings, or in the clearings themselves (Schwartz $\&$ Schwartz, 1949). When a male encounters a female in the short grass or at a distance across the clearing, he is likely to first see her head and neck. As the two birds come closer together, more of their bodies will become visible, and their social interactions will become more intense.

The male's sexual behavior sequence begins with approach to the female. He then grabs the female's plumage in his beak (usually a portion of the neck feathers) and mounts by placing both feet on the female's back. The sexual interaction ends with the male's making a series of cloacal thrusts (Wilson \& Bermant, 1972). In this behavior sequence, the sight of a female's head and neck may come to serve as a cue or a CS, and copulation or copulatory opportunity may serve as the US.

The natural sequence of quail sexual behavior has been analyzed in the laboratory in several different ways (see Domjan, 1998, for a review). In one procedure, a male bird is briefly allowed to view a female on the other side of a small window before being allowed to copulate with her. 
As this procedure is repeated, the male comes to spend increasing amounts of time near the window (e.g., Nash, Domjan, \& Askins, 1989). The increased interest in the female is due, at least in part, to a learned association between the cues of the female and copulatory opportunity (e.g., Domjan, Akins, \& Vandergriff, 1992).

Presenting a live female behind a window as the CS has some shortcomings as a model for the investigation of naturally occurring instances of Pavlovian conditioning. First, the sight of a live female can motivate learning in the absence of copulatory reinforcement (Holloway \& Domjan, 1993). Therefore, the sight of a live female may be more like a US than a CS. Second, a live female quail provides movement and other visual cues that are under poor experimental control. These problems can be solved by using a taxidermic model in place of a live female and by using only a small portion of the female's body to reduce the unconditioned effects of the female cues. An example of such a stimulus object is presented in Figure 1. The object is made of terry cloth and includes a taxidermically prepared female quail head and about $2 \mathrm{~cm}$ of neck feathers.

A number of characteristics make the female head model an ideal CS object for investigating the conditioned sexual behavior of male quail. First, such a CS object does not include enough female cues to elicit much sexual responding unconditionally. Second, the terrycloth portions of the object provide the necessary physical support to accommodate any conditioned copulatory behaviors that might develop. Finally, the presentation of the headed object as a CS just before the opportunity to copulate with a live female mimics the sequence of events that occurs when a male encounters a female at a distance or in the grass, approaches her, and then initiates copulation. The significance of the female plumage on the CS object can also be evaluated by testing the subjects with a similar terry-cloth object that lacks the taxidermically prepared female head (see Figure 1).

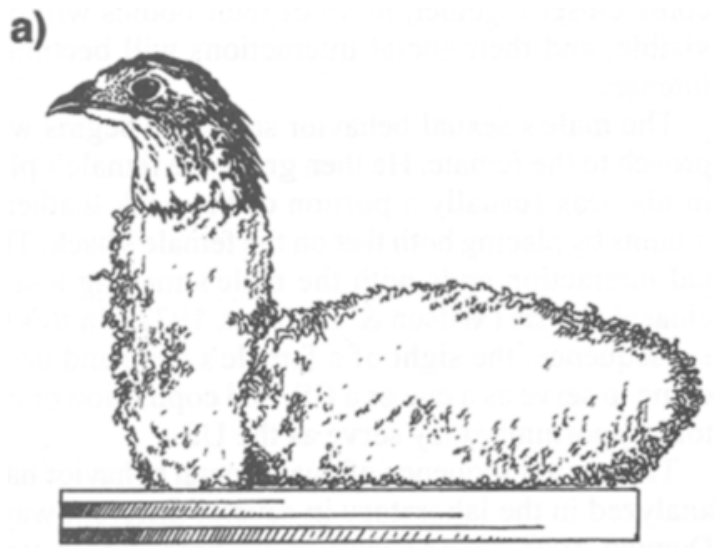

Early laboratory investigations have confirmed that the visual features of the head and neck, more than auditory or olfactory cues, are important to the regulation of sexual interactions in domesticated quail (Domjan \& Hall, 1986; Domjan \& Nash, 1988; see also Nash et al., 1989). More recent studies have indicated that a CS object that includes the cues of a female's head has some special properties in both nonassociative and associative learning paradigms. Repeated exposure to such a stimulus without sexual reinforcement results in a modest sensitization effect. Male quail come to spend more time near the CS object and also show modest elevations in their attempts to copulate with the object (Cusato \& Domjan, 1998). Such changes are not observed with a no-head CS. A CS object that includes female cues also produces different types of sexually conditioned responses. A no-head CS comes to elicit primarily conditioned approach responses. In contrast, the head CS elicits conditioned copulatory responses as well as approach (Cusato \& Domjan, 1998). Finally, the development of conditioned responding to the no-head CS can be blocked by a previously conditioned audiovisual cue. In contrast, the blocking effect does not occur with the head CS (Köksal, Domjan, \& Weisman, 1994).

The studies above clearly indicate that a terry-cloth object that includes cues of a female's head comes to elicit sexual responses more readily than a no-head object. Female species typical cues appear to be especially effective cues for sexual reinforcement. However, previous studies have provided little information about the mechanisms responsible for the facilitating properties of the female cues, nor have they identified the critical features of the female head that are important.

Explanations for why female cues facilitate male conditioned sexual responding may be formulated in the context of biological/evolutionary theory or in the context of general-process learning theory. In an evolutionary context, the facilitation effect may be viewed as an adaptive specialization of learning (Hinde \& Stevenson-Hinde,

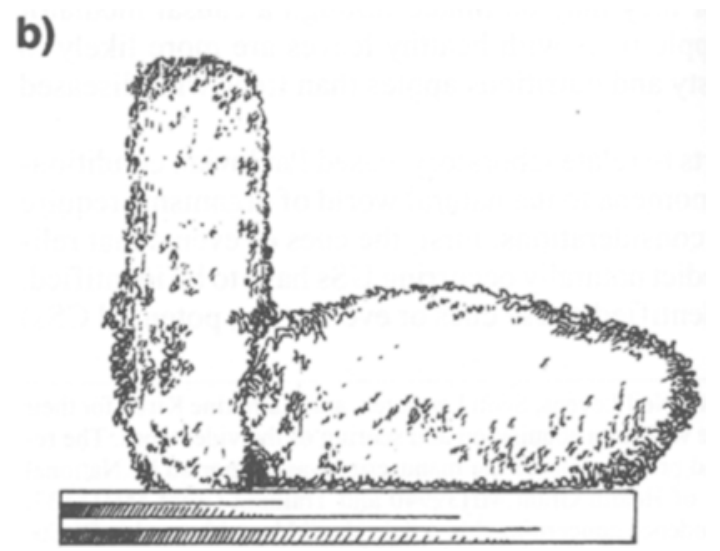

Figure 1. The CS objects used during the conditioning and test trials in Experiments 1 and 2. All objects were made of blue terry cloth filled with soft polyester fiber. They consisted of a vertical section positioned in front of a horizontal mounting pad. For some subjects, the CS object had either a blonde or a brown taxidermically prepared female head and partial neck, which were mounted on top of the vertical section (a). Other subjects received a CS object made entirely of terry cloth (b). (Reprinted with permission from Cusato \& Domjan, 1998 ). 
1973; Seligman \& Hager, 1972). Specialization may have evolved in the sexual behavior system of male quail because the cues of a female's head reliably precede and predict copulatory opportunity in the quail's natural environment. However, specialization may be less specific, affecting a variety of appetitive behavior systems including, but not limited to, the sexual behavior system. Within the context of general-process learning theory, males may respond more vigorously toward a CS with female head and neck cues because of the similarity of such a CS to the live female which provides copulatory reinforcement. CS-US similarity has been shown to facilitate the establishment of associations in several different conditioning paradigms (Rescorla \& Furrow, 1977; Testa, 1974).

The present experiments were conducted in order to examine the possible mechanisms responsible for the special efficacy of female cues in sexual conditioning. In Experiment 1, we addressed the CS-US similarity hypothesis by manipulating the physical attributes of the $\mathrm{CS}$. The resemblance of the CS object to the live female, which served as the US, was varied by manipulating the presence or absence of female plumage as well as the color of the female plumage, which was part of the CS object. Some males were conditioned with a CS that included female cues of the same color as those of the female US. Other males were exposed to a CS object containing female cues of a different color. A third group of males received a CS that was made entirely of terry cloth.

In Experiment 2, we investigated the extent to which the facilitation effect represents an adaptive specialization specific to the sexual behavior system by varying the properties of the US. The effects of the female cues in conditioning with a sexual US were compared with those in conditioning with a food US. If the facilitating properties of female head and neck cues reflect a specialization limited to sexual behavior, female cues should not facilitate conditioning with a food US. On the other hand, if female cues facilitate appetitive conditioning in general, comparable results should be obtained with the two USs.

\section{EXPERIMENT 1}

In Experiment 1, we investigated the CS-US similarity hypothesis by testing whether the enhanced responding to female cues observed in sexual conditioning would be affected by plumage color. Male domesticated quail respond to females, at least in part, on the basis of the color of a female's plumage. For instance, in an experiment designed to investigate the effects of early social experience on adult mate choice, Gallagher (1976; see also Gallagher, 1977) found that male domesticated quail raised with quail chicks that were either brown or albino subsequently preferred sexual partners whose plumage was similar to that of the chicks with which they were raised. Blohowiak and Siegel (1983) reported similar results using redhead, albino, and wild-type plumage colors. These results show that male quail exhibit sexual imprinting effects and are able to discriminate between potential sexual partners on the basis of plumage color. However, color preferences are not determined solely by early social experience. The plumage preferences of male quail can also be affected by differential reinforcement in adulthood (Nash \& Domjan, 1991; Nash et al., 1989).

In Experiment 1, we tested the role of plumage color as a possible factor in the effectiveness of female cues in sexual conditioning. Three types of CS objects were compared. Two of the CS types included the cues of a female's head. For one of these, the female cues were obtained from brown quail that were similar to those that the male subjects were exposed to during their rearing history. For the second set of CS objects, the female cues were obtained from blonde quail whose plumage was much lighter in color. A third type of CS object was made entirely of terry cloth and did not include female head cues. All three CS types were presented to brown male quail and were either paired or unpaired with the opportunity to copulate with a live brown female.

\section{Method}

Subjects. The experiment was conducted in two counterbalanced replications. Forty-eight adult male domesticated quail (Coturnix japonica) with brown or "normal" plumage served as experimental subjects. The males were 3-4 months old and sexually naive at the beginning of the experiment. Twelve adult female domesticated quail, also with brown plumage, served as copulation partners. The assignment of females to males was rotated throughout the experiment so that no male had access to the same female on consecutive daily trials.

All of the birds were selected from the breeding colony maintained at the University of Texas at Austin. At 1 month of age, they were removed from brooders and housed in metal quail cages (G.Q.F. Manufacturing Co., Savannah, GA). While in the metal cages, the male birds were housed individually and the female birds were housed in groups. All the birds were maintained on a 16:8-h light: dark cycle, which provided sufficient photostimulation to maintain the birds in reproductive condition.

Males were selected for participation on the basis of the results of a pretest for copulatory behavior. For the pretest, a female quail was placed in the male's home cage for $5 \mathrm{~min}$. Previous research has shown that this is sufficient for sexually active males to initiate copulatory behavior (Schein, Diamond, \& Carter, 1972). Only the males that made cloacal contact with the female during the 5-min pretest were selected. Two males that had passed the pretest consistently failed to copulate in the experimental chambers and were omitted from the analyses.

Apparatus. Twelve experimental chambers were used. Each chamber was $90 \mathrm{~cm}$ (wide) $\times 68.5 \mathrm{~cm}$ (high) $\times 120 \mathrm{~cm}$ (deep). The front access door and floor of each chamber were made of wire mesh; the ceiling and remaining walls were made of sealed plywood. A smaller compartment $(29.5 \times 35.5 \times 60.5 \mathrm{~cm})$ was attached adjacent to the experimental chamber, centered at floor level on a side wall. The side compartment was used to hold a live female bird during the conditioning trials. A $14 \times 16.5 \mathrm{~cm}$ vertically sliding door (the US door) separated the side compartment from the main experimental chamber. A 40 -W light bulb near the ceiling provided illumination. 
The CS was a blue terry-cloth object filled with soft polyester fiber. It consisted of a $10.8-\mathrm{cm}$ vertical section $(3.5 \mathrm{~cm}$ in diameter) positioned in front of a $6.5 \mathrm{~cm}$ (wide) $\times 5 \mathrm{~cm}$ (high) $\times 10.5 \mathrm{~cm}$ (long) horizontal mounting pad. For a third of the subjects, the CS was a taxidermically prepared brown female head with approximately $2.5 \mathrm{~cm}$ of neck feathers mounted on top of the vertical section. Another third of the subjects were exposed to a CS object that had a blonde female head and neck. The remaining third were conditioned with a CS object made entirely of terry cloth (see Figure 1). When not in use, the CS object was covered by a 19 (long) $\times 19$ (wide) $\times 15.8 \mathrm{~cm}$ (high) plywood hood. When the hood was down, it completely obscured the male's view of the CS. When the hood was raised, the male had full access to the CS object. The CS was secured to the floor approximately $17.5 \mathrm{~cm}$ from the door to the female compartment, in the middle of a marked area $45.5 \times 40 \mathrm{~cm}$.

\section{Procedure}

Prior to the start of each replication, the males were randomly assigned to one of two squads. Each squad was housed in the experimental chambers during alternate 24 -h periods. While one squad of subjects was in the experimental chambers, the other was housed in the colony cages. The birds that spent the previous night in the experimental chambers received their daily treatment trial the next morning. The birds were then exchanged so that the second squad could receive its trial that afternoon and remain in the chambers overnight. The alternate housing procedure began 8 days prior to the start of the conditioning trials. The subjects then received five daily sessions of habituation to movements of the hood that was to cover the CS object. The plywood hood in each chamber was raised and lowered two or three times during each session (in the absence of the CS object). The hood remained raised for $2 \mathrm{~min}$, and $10 \mathrm{~min}$ elapsed between each trial.

Each subject was assigned to one of six groups in a $3 \times 2$ factorial design. The groups differed in terms of the type of CS they received and whether the CS was paired with copulatory opportunity (US). One third of the subjects was exposed to a CS with a brown female head, one third was exposed to a CS with a blonde female head, and one third was exposed to a CS made entirely of terry cloth. Within each of these conditions, half of the males received the CS paired with the US, and the other half received the CS and the US in an unpaired fashion. Each subject received one trial a day for 13 days.

Conditioning trials began on the day following the habituation phase. For the paired subjects, a trial began when the hood was raised to expose the CS object. One minute later, the US door was opened to allow the male copulatory access to the female. The CS was covered by the hood immediately after the male made contact with the female, and the 2 birds were allowed to interact for $5 \mathrm{~min}$. The unpaired males were given $5 \mathrm{~min}$ access to a female $30-40 \mathrm{~min}$ prior to the 1-min CS presentation. This made the order of CS and US presentations "backward," but the interval between the US and CS was much longer than in typical backward conditioning procedures (Spetch, Wilkie, \& Pinel, 1981).

In order to obtain data on responding to the CS that was uncontaminated by prior exposure to the US that day, all the subjects were given $1 \mathrm{~min}$ of exposure to their respective CS objects, without access to a female on Days $1,4,7,10$, and 13. These test trials were recorded on videotape and were used to examine acquisition performance. However, since the acquisition data did not reveal anything that was not reflected in the postacquisition test trial, only data from the first and last test trial are presented.

Response measures. The test trials were scored for time spent near the CS (approach) and the number of grab responses directed toward the CS. A bird was considered to have approached the CS when it entered the $45.5 \times 40 \mathrm{~cm}$ marked area in which the CS was located, and a grab response was scored when the male held a portion of the CS (usually some part of the vertical section) in its beak. As in previous experiments of this nature, a careful distinction was made between peck and grab responses that were directed toward the CS objects. Pecks did not involve holding a portion of the CS object in the beak for any discernible period.

\section{Results}

Only the blonde headed CS elicited any measurable approach behavior $(M=0.94 \mathrm{sec})$ or grab responses $(M=$ $0.19)$ during the first test trial, which was conducted be-
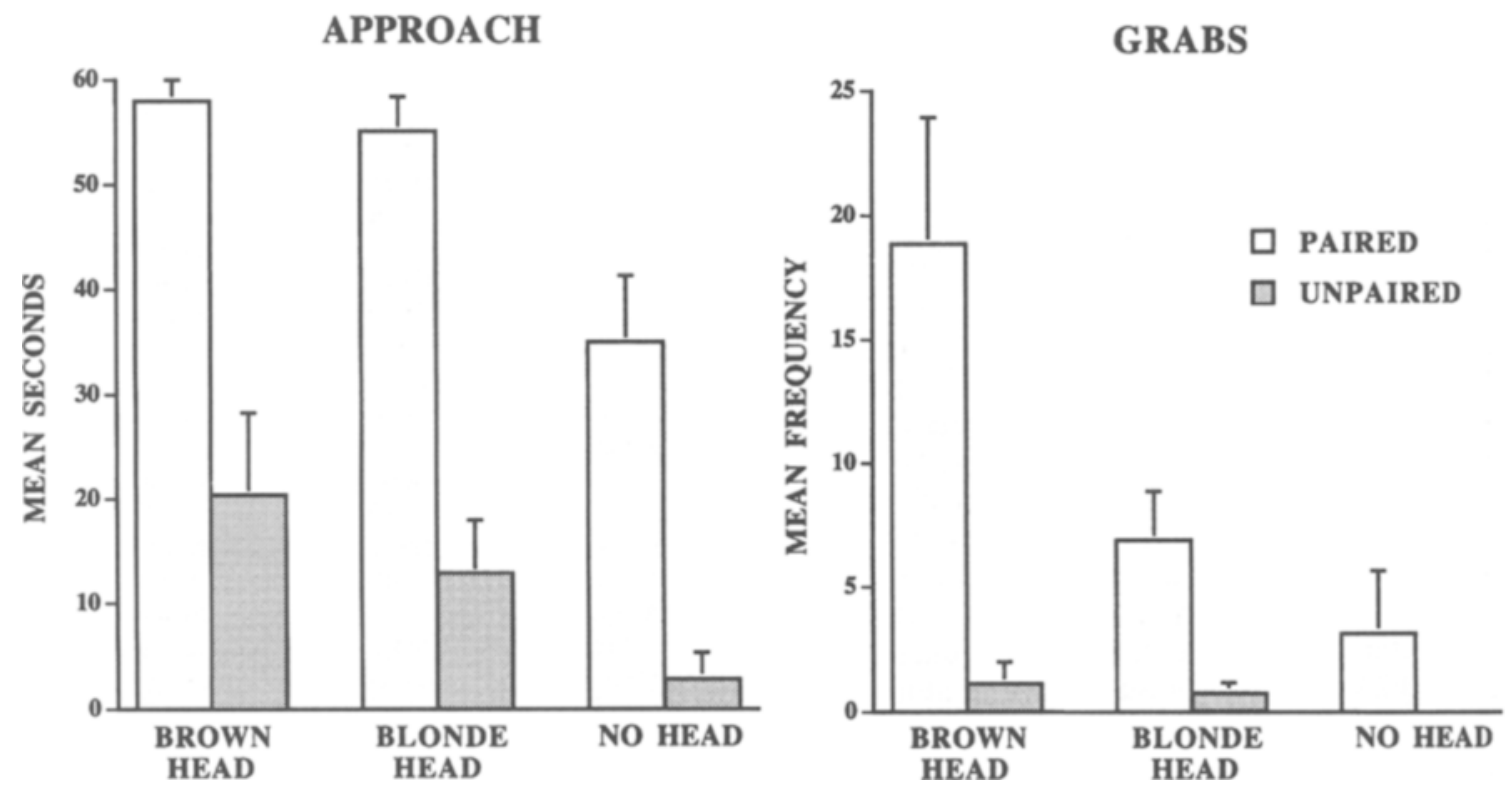

Figure 2. Mean $(+S E)$ responding to each type of CS object during the test session conducted at the end of Experiment 1 . Approach responses are displayed in the left panel and grab responses are shown in the right panel. Open and shaded bars represent data from paired and unpaired groups, respectively. 
fore any CS-US pairings. No approach or grab responses were evident with the brown headed CS or with the CS made entirely of terry cloth.

The results of the test trial conducted at the end of the experiment are summarized in Figure 2. Approach and grab responses were evaluated with separate analyses of variance (ANOVAs) in which CS type and CS-US pairings served as between-subjects variables. Each of the two responses was significantly affected by CS-US pairings. The paired groups exhibited significantly more approach and grab responses than did the unpaired groups $[F \mathrm{~s}(1,40)=82.63,22.75$, respectively, $p \mathrm{~s}<.01]$.

The type of CS object presented also influenced the behavior of the subjects. There was a significant main effect of CS type on approach behavior $[F(2,40)=8.58$, $p<.01]$ and on grab responses $[F(2,40)=6.99, p<.01]$. In addition, the interaction between CS type and CS-US pairings was significant for the grab response measure $[F(2,40)=5.47, p<.01]$.

Student-Newman-Keuls post hoc comparisons $(p<$ .05 ) were conducted in order to further explore the effects of CS type on conditioned approach and grab responding. For the approach measure, the headed CSs elicited significantly more responding than did the no-head CS, but plumage color on the headed CS objects was of little consequence. Approach to the brown headed CS did not differ significantly from approach to the blonde headed CS.

In contrast to the approach response, the grab response revealed significant differences as a function of plumage color. Virtually no grabs were observed among the unpaired groups. Analysis of the grab response for just the paired groups revealed a significant main effect of CS type $[F(2,19)=5.72, p<.05]$, and Newman-Keuls tests $(p<$ .05 ) indicated that the paired subjects grabbed the brown headed CS significantly more often than they grabbed either the blonde CS or the no-head CS.

\section{Discussion}

The present findings confirm and extend the findings from previous experiments in several ways. The subjects responded more vigorously to the CS when it included a taxidermic female head. This outcome was observed with both the approach and grab response measures. However, the grab response measure showed some additional effects as well. The subjects made a substantial number of grab responses only when the CS object was paired with copulatory opportunity, and they showed more conditioned grab responding to the brown headed CS than to the blonde headed CS.

The present finding that the headed CS objects elicited more approach and grab responding than did the nohead CS object confirms previous results (Cusato \& Domjan, 1998; Köksal et al., 1994) and is compatible with the CS-US similarity hypothesis. The males may have responded more vigorously toward the CSs with female head and neck cues because these CSs shared common attributes with the live female, which provided the sexual US. The similarity between the CS and the US may have also been responsible for the fact that the males in Experiment 1 directed more conditioned grab responses toward the brown than toward the blonde headed CS. The brown headed CS object more closely resembled the live brown females that provided copulatory opportunity than did the blonde headed CS. However, the fact that both the brown and the blonde headed CS objects elicited similar degrees of approach behavior is not consistent with the CS-US similarity hypothesis. Therefore, CS-US similarity cannot account for all of the present findings.

The curious finding from Experiment 1 that plumage color influenced conditioned grab behavior more than it affected conditioned approach behavior is consistent with the concepts of behavior systems theory. Behavior systems theories have been developed to characterize how rats learn about feeding and defensive behavior (Fanselow, 1994, 1997; Timberlake, 1983, 1994) and how quail learn about copulatory opportunity (Domjan, 1994). In these behavior systems, different types of responses are presumed to be sensitive to different types of environmental stimuli. These dynamic factors interact to determine the form of the learned behavior. It may be that approach behavior is controlled primarily by distal visual cues, such as the shape of a female's head, whereas grab responses may be controlled by more proximal cues, such as color and texture. From this perspective, males would be just as likely to approach brown cues as they would blonde cues. Once the male is in close proximity, however, the specific attributes (e.g., color) of female plumage would become more important. The differential development of conditioned approach and grab responding is also consistent with traditional views in which appetitive responses (e.g., approach) are regarded as less stimulus bound than the consummatory responses that occur later in the behavioral sequence (Baerends, 1988; Eibl-Eibesfeldt, 1970; Tinbergen, 1951).

\section{EXPERIMENT 2}

In our previous studies of the efficacy of female cues in conditioning, sexual reinforcement has served as the US. Female cues may be especially effective in sexual conditioning situations because such cues are relevant to finding a potential sexual partner in the quail's natural environment. Alternatively, the efficacy of female cues may reflect a less specific specialization of appetitive behavior systems in general. We conducted Experiment 2 in order to decide between these alternatives by comparing conditioning with a sexual US to conditioning with a food US. If the effectiveness of female cues represents a specialization limited to sexual behavior, a CS object that includes the cues of a female head should not facilitate conditioning with a food US. On the other hand, if the facilitation effect represents a less specific specialization relevant to appetitive behaviors in general, similar results should be obtained with sex and food as the US.

A $2 \times 2 \times 2$ factorial design was used. For half the subjects, the CS object included a taxidermically pre- 
pared brown female head with about $2.5 \mathrm{~cm}$ of neck feathers. The remaining birds were conditioned with a CS that lacked female species-typical cues. With each CS type, some of the subjects received copulatory opportunity as the US, whereas others received food as the US. Finally, these conditions were further subdivided so that some males received the CS paired with the US, whereas others received the CS and US in an unpaired fashion.

\section{Method}

Subjects. The experiment was conducted in two counterbalanced replications with 48 adult male domesticated quail (Coturnix japonica), 4-10 months old. The subjects were given a pretest for copulatory behavior in their home cages, as was done in Experiment 1 . Fourteen of the males in the first replication had previously served in an unrelated experiment involving training in a straightalley runway. These subjects were distributed equally across the present conditions. The remaining males were experimentally naive prior to their participation. Sixteen adult female domesticated quail served as copulation partners. The assignment of females to males was rotated so that no male had access to the same female on consecutive trials.

Apparatus. The apparatus was the same as in Experiment 1. The CSs also were similar to those used in Experiment 1. Half of the subjects were conditioned with a CS that had a taxidermically prepared female head with approximately $2.5 \mathrm{~cm}$ of neck feathers mounted on top of the vertical section. (The head was taken from a female with normal brown plumage.) The other subjects were conditioned with a CS object made entirely of terry cloth (see Figure 1). When not in use, the CS object was covered by a $19 \mathrm{~cm}$ (long) $\times$ $19 \mathrm{~cm}$ (wide) $\times 15.8 \mathrm{~cm}$ (high) plywood hood. When the hood was down, it completely obscured the male's view of the CS. When the hood was raised, the male had full access to the CS object. The CS was secured to the floor approximately $17.5 \mathrm{~cm}$ from the door to the female compartment, in the middle of a marked area measuring $45.5 \times 40 \mathrm{~cm}$.

\section{Procedure}

Habituation. Prior to the start of each replication, the male birds were randomly assigned to one of two squads. Each squad was housed in the experimental chambers during alternate 24 -h periods for habituation. During this preliminary phase, the subjects were also habituated to movements of the hood that was to cover the CS object, as in Experiment 1 . In addition, each subject was food deprived to $80 \%$ of its free-feeding weight. The birds were given 90 min access to food in their home cages each day until the $80 \%$ target weight was reached. In order to maintain the target weight, thereafter, they were given 60 -min access to food at least $45 \mathrm{~min}$ after the daily trials were completed.

Following the 10-day habituation phase, the subjects were housed in their colony cages. They were moved to the experimental chambers $30 \mathrm{~min}$ prior to each training trial and remained there for $30 \mathrm{~min}$ after the trial was completed.

Within each squad, the subjects were assigned to one of eight groups. Four of the groups received sexual opportunity as the US; the other four received food as the US. These groups were equally divided in such a way that half of the males were conditioned with a CS object that had a female head, and the other half were conditioned with a CS object made entirely of terry cloth. Finally, within each of these conditions, half of the males received the CS paired with the US and the other half received the CS and US in an unpaired fashion. Six subjects were originally assigned to each experimental condition. However, 1 subject (in one of the unpaired groups) was dropped from the experiment because of illness.
The day before the conditioning trials began, the subjects were given 5-min access to their respective USs in the experimental chambers. The hoods were raised and locked in place so that the males had an unobscured view of the US door. Males that had copulatory opportunity paired with a CS were presented with the US (i.e., a live female from the side compartment). The males that received copulatory opportunity unpaired with a CS were presented with a live female through the front access gate. All of the subjects in these conditions copulated during the 5-min US-alone period.

The subjects that had food paired with a CS needed to be trained to approach the US door. The food cup was presented to the birds by raising the US door. Once the male found the food, he was allowed to eat for $1 \mathrm{~min}$ before the door was lowered. After a 10-min intertrial interval, the door was raised again, and the male was allowed to eat for another minute. Five 1 -min eating periods were given to each male. The subjects that received food unpaired with a CS were presented with a food cup through the front access gate and were allowed to eat for an uninterrupted 5 -min period.

Conditioning. Conditioning began 1 day following the US-alone trials, and the subjects received one trial per day. For the subjects in the paired condition, a trial began when the hood was raised to expose the CS object. Thirty seconds later, the US door was opened to allow the male access to the US (either food or a female). After $5 \mathrm{~min}$, the CS was covered by the hood and access to the US was terminated. The subjects in the unpaired condition received 5-min access to the US 25-30 min prior to presentation of the CS for $30 \mathrm{sec}$. Once the daily trials were completed, all of the birds that received food as the US were given 5-min access to a female 45-60 min after they were returned to their colony cages. This was done to equate the copulatory experience of the food-US subjects with the sexual experience of the subjects for whom copulation served as the US.

In order to obtain data on responding to the CS that was uncontaminated by prior exposure to the US that day, all subjects were given 1-min exposure to their respective CS objects without a US presentation on Days 1, 6, and 11 of training. As in Experiment 1, these test trials were recorded on videotape and scored for approach and grab behavior. In addition, because the approach and grab measures did not differentiate between the US types, the duration of each grab, as well as the frequency of pecks, mounts, and cloacal contacts were scored. However, because grab duration and peck frequency showed a pattern similar to grab frequency, these data are not explicitly presented. A mount response was scored when the male placed both feet on the CS object at the same time. A cloacal contact response was scored when the male arched its back, bringing its cloaca in contact with the back of the CS object while making the mount response. As in Experiment 1, only the data from the first and last of the test trials are discussed.

\section{Results}

The first test trial was conducted before any conditioning trials and therefore served to indicate whether the different CS types elicited different levels of unconditioned responding. The approach, grab, mount, and cloacal contact responses were analyzed in separate ANOVAs in which US type, CS type, and CS-US pairings served as variables. These analyses indicated that the subjects spent more time approaching the CS object that included a female head $(M=14.7 \mathrm{sec})$ than they did the CS made entirely from terry cloth $(M=0.6 \mathrm{sec})[F(1,39)=8.08, p<$ $.01]$. The headed CS also elicited more mount responses $(M=1.21)$ than did the no-head $\operatorname{CS}(M=0)[F(1,39)=$ $4.58, p<.05]$. These findings indicate that the CS with female cues elicited a moderate level of approach and 

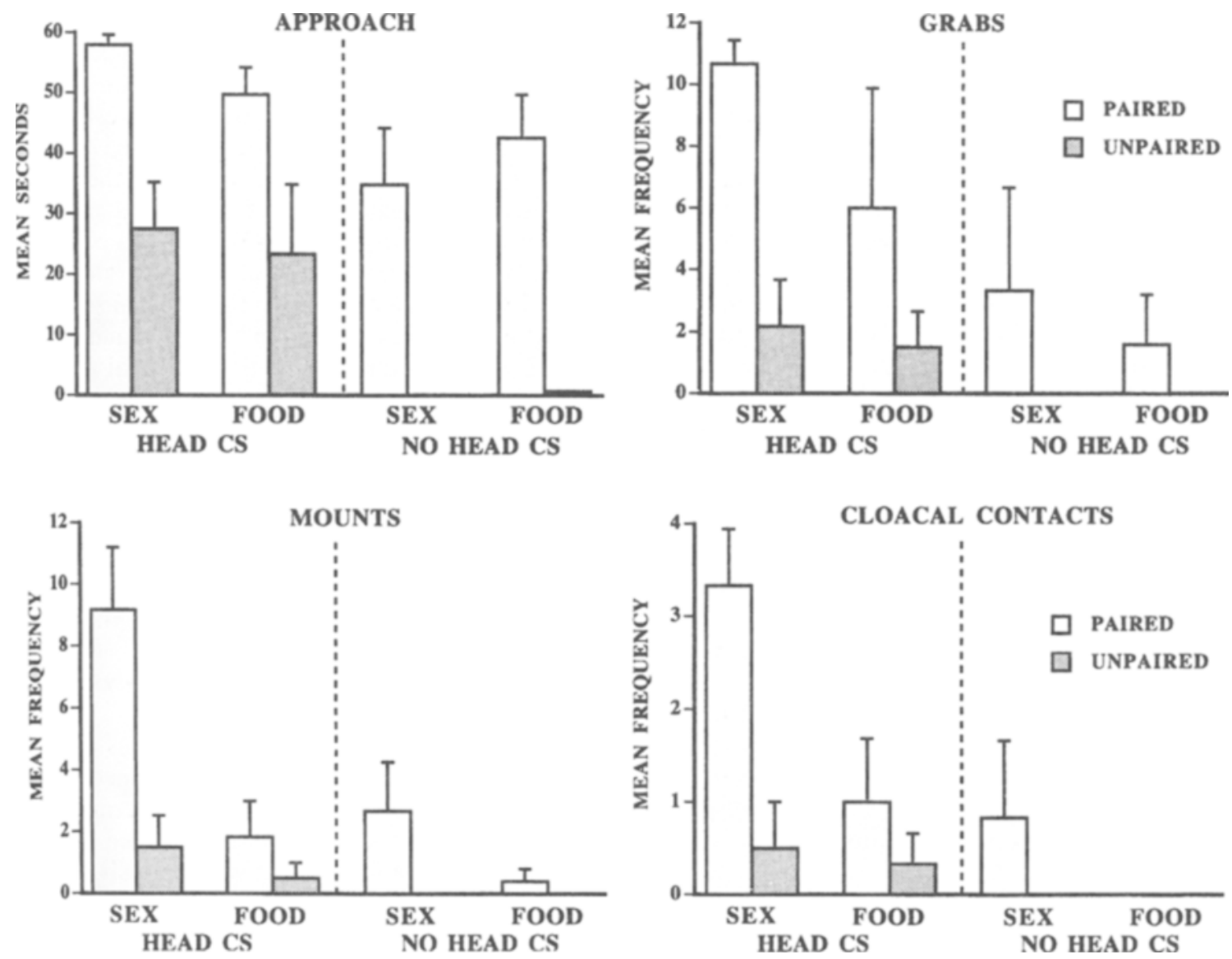

Figure 3. Mean $(+S E)$ responding to each type of $C S$ object during the test session conducted at the end of Experiment 2. The data are further separated by the type of US used during the conditioning trials. Approach and grab responses are displayed in the top panels, and mount and cloacal contact responses are shown in the bottom panels. Open and shaded bars represent data from paired and unpaired groups, respectively.

mount behavior unconditionally. However, no significant differences were obtained with the grab and cloacal contact responses. In addition, as expected, none of the analyses revealed any significant effects of US type or CS-US pairings, because the first test was conducted before the first conditioning trial.

The results of the test trial conducted at the end of the experiment are summarized in Figure 3. As was evident with the approach and mount responses before conditioning, the CS that included female cues elicited more vigorous responding overall than did the no-head CS. ANOVAs indicated a significant main effect of CS type for the approach, grab, mount, and cloacal contact responses $[F \mathrm{~s}(1,39)=18.29,8.44,10.01,9.40$, respectively, $p \mathrm{~s}<.01]$. The level of responding was also significantly affected by CS-US pairings. Paired groups showed significantly more approach, grab, mount, and cloacal contact responses than did the unpaired groups $[F \mathbf{s}(1,39)=$ $50.50,11.44,14.78$, and 9.40 , respectively, $p$ s $<.01]$. The main effects of US type failed to reach significance for the approach and grab measures but were significant for the mount $[F(1,39)=11.40, p<.01]$ and cloacal contact $[F(1,39)=5.56, p<.05]$ measures.

Neither the nature of the US nor the nature of the CS influenced conditioning of the approach and grab responses. Both the food and sexual USs produced similar increments in these behaviors as a function of CS-US pairings, with the result that interactions between US type and pairings were not significant for either response measure $(F \mathbf{s}<1)$. The interactions between CS type and pairings were also not significant for the approach and grab response measures $[F \mathrm{~s}(1,39)=1.12$ and 2.32 , respectively, $p s>.10]$, indicating that similar associative effects occurred whether or not the CS included female cues. The triple interactions (CS type $\times$ US type $\times$ CS-US pairings) were also not significant for these response measures.

Conditioning of the mount and cloacal contact responses, unlike the approach and grab responses, depended on both the nature of the CS and the nature of the US. Sexual reinforcement was much more effective than the food US in conditioning mount and cloacal contact responses. In addition, the conditioning of the mount and 
cloacal contact responses was more successful when the CS object included female cues. The analyses revealed significant interactions between US type and pairings for both mount $[F(1,39)=7.51, p<.01]$ and cloacal contact $[F \mathrm{~s}=4.51, p<.05]$ responses, and the interactions between CS type and pairings were marginally significant $\left[F_{\mathrm{s}}(1,39)=3.57\right.$ and 3.56 , respectively, $\left.p \mathrm{~s}<0.07\right]$. Subsequent comparisons with the Newman-Keuls test $(p<$ .05 ) indicated that the subjects that received the headed CS paired with sexual reinforcement made significantly more mount and cloacal contact responses than did the subjects in each of the other groups, which did not differ from each other. These results indicate that the mount and cloacal contact responses became conditioned only when the sexual US was used and the CS included cues of a female's head.

\section{Discussion}

The results of Experiment 2 reveal both similarities and differences in the two types of appetitive conditioning that were compared. Food and sexual reinforcement were equally effective in conditioning approach and grab responses. Furthermore, with both types of USs, the inclusion of female cues increased these responses. In contrast, sexual reinforcement was much more effective than food in conditioning mount and cloacal contact responses, and these responses became conditioned only when the CS included female cues.

The contrasting results that occurred with food and sexual reinforcement are related to the types of responses that were elicited by the two USs. The male quail approach and grab pieces of food, and they also show approach and grab responses in their sexual interactions with the females. Therefore, approach and grab responses represent common responses to the appetitive USs used in the present experiment. In contrast, mount and cloacal contact responses were elicited only by a potential copulatory partner and therefore were more specific to the US employed. The fact that the responses modified by conditioning were related to the types of responses that were elicited by each US is consistent with stimulus-substitution views of Pavlovian conditioning (Jenkins \& Moore, 1973; Pavlov, 1927; but see Timberlake \& Grant, 1975). After repeated CS-US pairings, the subjects responded to the CS as if it were a substitute or surrogate for the US. The behaviors elicited by the CS resembled the behaviors that occurred when the US was encountered.

Consistent with previous findings (Cusato \& Domjan, 1998; Köksal et al., 1994) and the results of our Experiment 1 , the CS object that included the cues of a female's head elicited more responding than the no-head CS. With responses that are common to the feeding and sexual behavior systems (approach and grab), this facilitation was not a function of CS-US pairings. Thus, the increased responding elicited by female cues appears to reflect a performance effect rather than a learning effect. In contrast, with the uniquely sexual responses (mounts and cloacal contacts), the facilitation effect of female cues was evident only when the CS was paired with copulatory opportunity. Thus, the facilitation effect of female cues on mount and cloacal contact responding was more clearly a feature of conditioned behavior.

Experiment 2 was designed to test whether the special properties of female species typical cues are limited to the sexual behavior system. On the basis of the results, the answer seems to depend on the generality of the response that is measured. Appetitive responses (approach and grab) that are common to both food and sexual situations were facilitated by both the sexual and the food US. In contrast, responses specific to the sexual behavior system (mounts and cloacal contacts) were facilitate only when a sexual US was used in the conditioning trials. Therefore, all of the findings are consistent with the conclusion that female cues facilitate responding whenever the measured response is appropriate to the US that is used. This suggests that the facilitation effect is a general property of appetitive conditioning situations.

\section{GENERAL DISCUSSION}

Although traditional laboratory studies of Pavlovian conditioning have been primarily concerned with identifying the underlying mechanisms of learning phenomena, investigators are becoming interested in how these underlying mechanisms affect what animals learn in their natural environment. Efforts to explore naturally occurring instances of learning require the identification of stimuli that may acquire predictive value in natural surroundings. Often these are cues that have inherent spatial or other relations to the biologically significant US that they signal. Therefore, it is important to examine how these potential preexisting relationships might influence the course of the learning that occurs.

In the sexual behavior of male quail, the visual features of a female's head and neck reliably precede, and may come to predict, the opportunity to engage in sexual behavior. Because of this, the cues of a female's head may be of special relevance to male copulatory behavior. Consistent with this interpretation, previous research has shown that female cues are more readily associated with sexual reinforcement than are arbitrary CSs (Cusato \& Domjan, 1998; Köksal et al., 1994). In order to replicate and extend these previous findings, we examined the role of plumage color and the effects of female cues in a nonsexual appetitive conditioning procedure.

The results of Experiment 1 confirm that the inclusion of cues of a female head on a CS object facilitates approach and grab responding. The facilitation effect on approach behavior was evident with both familiar brown plumage and novel blonde plumage. However, conditioned grab responses increased only when brown plumage was used. The results obtained with the grab response in Experiment 1 , as well as in previous demonstrations of facilitated conditioned responding to $\mathrm{CS}$ objects that included the cues of a female's head (Cusato \& Domjan, 1998; Kök- 
sal et al., 1994), may be explained within the context of general process learning theory by appealing to CS-US similarity mechanisms. A CS that includes features of the female quail may come to elicit more conditioned sexual behavior because such a CS is more similar to the live female US. Facilitated conditioned responding based on CS-US similarity has been reported in other conditioning preparations as well (Rescorla \& Furrow, 1977; Testa, 1974). However, the CS-US similarity account has difficulty explaining why the brown and the blonde headed CS objects elicited similar degrees of approach behavior in Experiment 1.

The CS-US similarity account is also difficult to reconcile with the results of Experiment 2. In Experiment 2, approach and grab responses increased when the CS included female features, whether the US was food or sexual reinforcement. It is difficult to conceive how adding female cues to a CS object made that object more similar to food. Therefore, the CS-US similarity hypothesis does not explain why responding was elevated in conditioning with food when the CS included the cues of a female's head.

In Experiment 2, we also addressed the boundaries of the facilitation effect by comparing two disparate appetitive conditioning situations-sexual conditioning and conditioning with a food US. The results indicate that female cues facilitate responding in both appetitive conditioning situations, provided that the measured response is relevant to the US that is employed. Mount and cloacal contact responses, which are elicited by sexual USs, were facilitated by female cues when a sexual US was used. Approach and grab responses, which are elicited by both food and sexual USs, were facilitated by the presence of female cues irrespective of the US that was used.

Why might female head cues facilitate responding in conditioning with both a sexual US and a food US? The cues of a female's head may have facilitated responding in both sexual and feeding situations because, for the domesticated quail, they are both appetitive social situations. The social nature of sexual behavior is obvious. Males have to be responsive to female cues in order to be successful in their sexual and copulatory behavior. In addition, as we have suggested, the cues of a female's head may reliably precede sexual reinforcement in a male's natural surroundings.

The available evidence suggests that the cues of a female's head may also reliably precede and accurately predict feeding opportunities. Both as chicks and as adults, quail exhibit patterns of social behavior and social feeding that provide opportunities for species-typical cues to acquire predictive significance. During the first few days post hatch, domesticated quail feed in close proximity to the mother hen and their siblings (Mills, Crawford, Domjan, \& Faure, 1997; Orcutt \& Orcutt, 1976). In addition, the quail hen provides feeding information to the chicks by using a behavioral pattern similar to the tidbitting behavior of males (Mills et al., 1997; see also
Galef, 1996). When the hen finds food, she emits a food call that serves to alert and attract the chicks. When the chicks are close by, the hen pecks at the food and drops bits of food in front of them. Under these circumstances, the cues of the hen can become signals predictive of feeding opportunities for the chicks.

Visual features of conspecifics also may be associated with feeding opportunities later in life. Field reports indicate that feral populations of domesticated quail form pair bonds that last the entire breeding season (Mills et al., 1997; Orcutt \& Orcutt, 1976; see also Nichols, 1991). While they maintain their pair bond, male-female pairs are bound to engage in a variety of activities together, including feeding. In addition, families composed of a male, a female, and their chicks may temporarily congregate with other families in loose coveys to feed at attractive feeding sites (Schwartz \& Schwartz, 1949). These behavior patterns can also lead to frequent pairings of the visual cues of conspecifics with feeding opportunities.

The considerations above suggest that the cues of a female's head will enhance responding in a variety of appetitive social situations. However, the special efficacy of female cues may extend beyond appetitive situations. Female cues may be especially salient for male quail always attracting more attention than CSs without female cues. Adding cues of a female's head to a CS may increase the salience of the CS, generally. According to this interpretation, subjects will respond more vigorously to a head CS than to a no-head CS, regardless of the US that is employed. In particular, the general salience interpretation suggests that a head CS should lead to more vigorous responding in aversive conditioning situations as well. Unfortunately, the available evidence does not permit us to decide between this general salience account and an explanation limited to appetitive conditioning situations.

\section{REFERENCES}

BaERends, G. P. (1988). Ethology. In R. C. Atkinson, R. J. Hernstein, G. Lindsey, \& R. D. Luce (Eds.), Stevens' Handbook of experimental psychology (Vol. 1, pp. 765-830). New York: Wiley.

Blohowiak, C. C., \& Siegel, P. B. (1983). Plumage phenotypes and mate preferences in Japanese quail: Sexual imprinting. Behavioural Processes, 8, 255-275.

Cusato, B., \& Dom Jan, M. (1998). Special efficacy of sexual conditioned stimuli that include species typical cues: Tests with a conditioned stimuli preexposure design. Learning \& Motivation, 29, 152-167.

DOM JAN, M. (1994). Formulation of a behavior system for sexual conditioning. Psychonomic Bulletin \& Review, 1, 421-428.

DOM JAN, M. (1998). Going wild in the laboratory: Learning about species typical cues. In D. L. Medin (Ed.), The psychology of learning and motivation (Vol. 38, pp. 155-186). San Diego: Academic Press.

Dom Jan, M., Akins, C., \& VAndergrifF, D. H. (1992). Increased responding to female stimuli as a result of sexual experience: Tests of mechanisms of learning. Quarterly Journal of Experimental Psychology, 45B, 139-157.

DOM JAN, M., \& HaLL, S. (1986). Determinants of social proximity behavior in Japanese quail (Coturnix coturnix japonica): Male behavior. Journal of Comparative Psychology, 100, 59-67. 
DOM JAN, M., \& NASH, S. (1988). Stimulus control of social behavior in male Japanese quail, Coturnix coturnix japonica. Animal Behaviour, 36, 1006-1015.

EIBL-EIBESFELDT, I. (1970). Ethology: The biology of behavior. New York: Holt, Rinehart \& Winston.

FANSELOW, M. S. (1994). Neural organization of the defensive behavior system responsible for fear. Psychonomic Bulletin \& Review, 1 , 429-438.

Fanselow, M. S. (1997). Species-specific defensive reactions: Retrospect and prospect. In M. E. Bouton \& M. S. Fanselow (Eds.), Learning, motivation, and cognition (pp. 321-341). Washington, DC: American Psychological Association.

GALEF, B. G. (1996). Social influences on food preferences and feeding behaviors of vertebrates. In E. D. Capaidi (Ed.), Why we eat what we eat-The psychology of eating (pp. 207-23I). Washington, DC: American Psychological Association.

GALLAGHER, J. (1976). Sexual imprinting effects of various regiments of social experience on mate preference in Japanese quail. Behaviour. 57, 91-115.

GallaGHER, J. (1977). Sexual imprinting: A sensitive period in Japanese quail (Coturnix coturnix japonica). Journal of Comparative \& Physiological Psychology, 91, 72-78.

Hinde, R. A., \& Stevenson-Hinde, J. (Eds.) (1973). Constraints on learning. New York: Academic Press.

Hollis, K. L. (1982). Pavlovian conditioning of sign-centered action patterns and autonomic behavior: A biological analysis of function. In J. S. Rosenblatt, R. A. Hinde, C. Beer, \& M. C. Busnel (Eds.), Advances in the Study of Behavior (Vol. 12, pp. 1-64). New York: Academic Press.

HoLLis, K. L. (1997). Contemporary research on Pavlovian conditioning: A "new" functional analysis. American Psychologist, 52, 956-965.

Holloway, K. S., \& Dom Jan, M. (1993). Sexual approach conditioning: Unconditioned stimulus factors. Journal of Experimental Psychology: Animal Behavior Processes, 19, 38-46.

JENkINS, H. M., \& MoORE, B. R. (1973). The form of the auto-shaped responses with food or water reinforcers. Journal of the Experimental Analysis of Behavior, 20, 163-181.

KaWAHARA, T. (1967). Wild Coturnix quail in Japan. Quail Quarterly, 4, 62-63.

KökSAL, F., Dom Jan, M., \& WeISMAN, G. (1994). Blocking of the sexual conditioning of differentially effective conditioned stimulus objects. Animal Learning \& Behavior, 22, 103-111.

Mills, A. D., Crawford, L. L., Dom jan, M., \& Faure, J. M. (1997) The behavior of the Japanese of domestic quail Coturnix japonica. Neuroscience \& Biobehavioral Reviews, 21, 261-281.

NASH, S., \& DOM JAN, M. (1991). Learning to discriminate the sex of conspecifics in male Japanese quail (Coturnix coturnix japonica): Tests of "biological constraints." Journal of Experimental Psychology: Animal Behavior Processes, 17, 342-353.
Nash, S., Dom Jan, M., \& Askins, M. (1989). Sexual-discrimination learning in male Japanese quail (Coturnix coturnix japonica). Journal of Comparative Psychology, 52, 415-419.

Nichols, C. R. (1991). A comparison of the reproductive and behav ioral differences in feral and domestic Japanese quail. University of British Columbia: Unpublished M.S. thesis.

OrCUTT, F. S., \& OrCuTT, A. B. (1976). Nesting and parental behavior in domestic common quail. $A u k, 93,135-141$.

Pavlov, I. P. (1927). Conditioned reflexes (G. V. Anrep, Trans.). London: Oxford University Press.

Rescorla, R. A., \& Furrow, D. R. (1977). Stimulus similarity as a determinant of Pavlovian conditioning. Journal of Experimental Psychology: Animal Behavior Processes, 3, 203-215.

Schein, M. W., Diamond, M., \& CarTer, C. S. (1972). Sexual performance levels of male Japanese quail (Coturnix coturnix japonica). Animal Behaviour, 20, 61-66.

SChWARTZ, C. W., \& SchwarTz. E. R. (1949). A reconnaissance of the game birds in Hawaii. Hilo: Hawaii Board of Commissioners of Agriculture and Forestry.

Seligman, M. E. P., \& Hager. J. L. (EDS.) (1972). Biological houndaries of learning. New York: Appleton-Century-Crofts.

SPETCH, M. L., WiLkie, D. M., \& Pinel., J. P. J. (1981). Backward conditioning: A reevaluation of the empirical evidence. Psvchological Bulletin, 89, 163-175.

Taka-Tsukasa, N. (1935). Coturnix coturnix japonica Teminick et Schlegel. In The birds of Nippon (Vol. 1, pp. 204-238). London: Whitherby.

TESTA, T. J. (1974). Causal relationships and the acquisition of avoidance responses. Psychological Review, 81, 491-505.

Timberlake, W. (1983). The functional organization of appetitive behavior. Behavior systems and learning. In M. D. Zeiler \& P. Harzem (Eds.), Biological factors in learning (Advances in Analysis of Behaviour, Vol. 3, pp. 177-221). Chichester, U.K.: Wiley.

TimberLaKe, W. (1994). Behavior systems, associationism, and Pavlovian conditioning. Psychonomic Bulletin \& Review, 1, 405-420.

Timberlake. W.. \& Grant, D. L. (1975). Auto-shaping in rats to the presentation of another rat preceding food. Science, 190, 690-692.

TINBERGEN, N. (1951). The study of instinct. London: Oxford University Press.

WETHERBEE, D. K. (1961). Investigations in the life history of the common Coturnix. American Midland Naturalist, 65, 168-186.

Wilson, M. I., \& Bermant, G. (1972). An analysis of social interactions in Japanese quail (Coturnix coturnix japonica). Animal Behaviour, 20, 252-258.

(Manuscript received May 7, 1999; revision accepted for publication February 11,2000 .) 